\title{
DELIBERATION DISCONNECTED: WHAT IT TAKES TO IMPROVE CIVIC COMPETENCE
}

\author{
ARTHUR LUPIA* \\ I \\ INTRODUCTION
}

Webster's Dictionary defines a person as competent if he or she has "requisite or adequate ability or qualities." Synonyms for competent include sufficient and able, where the definition for able includes "having sufficient power, skill, or resources to accomplish an object" and "marked by intelligence, knowledge, skill, or competence."

Such definitions are worth noting because concerns about a special kind of competence motivate many public and private activities, as well as a widely read strain of contemporary philosophy. The competence in question is civic competence, by which I mean the citizenry's ability to accomplish well-defined tasks - particularly in their roles as voters, jurors, or legislators. ${ }^{3}$

Civic competence is a central preoccupation of people who want citizens to base political choices on a broad and accurate understanding of their conse-

Copyright (C) 2002 by Arthur Lupia

This article is also available at http://www.law.duke.edu/journals/65LCPLupia.

* Professor of Political Science, University of Michigan. I thank Donald R. Kinder, Michael A. Nebb, Arlene Saxonhouse, all participants at the Duke University School of Law's conference entitled "The Law of Politics," as well as the University of Michigan's National Election Studies Fellows Workshop, for helpful comments.

1. WebSTER's NeW COLLEgiate Dictionary 227 (1st ed. 1981).

2. Id. at 3 .

3. I focus on competence as a technical skill. By this I mean the following: Suppose that a person who knows facts $X, Y$, and $Z$ can perform task $T$. It is consistent with the definition given above to call this person "competent at performing T." In politics, scholars and pundits often use survey responses to draw conclusions about the competence of citizens as voters. Their arguments take the form: "Person $A$ does not know fact $X$ or $Y$ or $Z$, therefore Person $A$ will cast a vote in election $T$ incompetently." Proving such arguments requires a demonstration that knowledge of $X, Y$, and $Z$ is necessary for competence (that is, that no subset of these facts or alternate set of facts may also allow the successful performance of $T$ ). Critics who make broad claims about civic competence regularly fail even to attempt such proofs. For example, evidence that citizens cannot provide correct answers to common political survey questions is equivalent to observing that a person does not know fact $Z$ in the example above. Many critics cite such data as evidence of citizens' incompetence as voters. Such conclusions, however, are premature. Drawing these types of conclusions without completing the proof leaves critics vulnerable to confounding recall of what may be little more than political trivia with the ability to perform a discrete task, such as competently choosing a candidate from a limited menu. In other words, it leaves critics vulnerable to a claim of general incompetence at judging voter competence. See Arthur Lupia \& Richard Johnston, Are Voters to Blame? Voter Competence and Elite Maneuvers in Referendums, in REFERENDUM DEMOCRACY: CITIZENS, ELITES AND DELIBERATION IN REFERENDUM CAMPAIGNS 193-95 (Matthew Mendelsohn \& Andrew Parkin eds., 2001). 
quences. ${ }^{4}$ Such desires, however, are dashed by evidence that citizens spend little time and effort engaging in politics. The finding that many Americans cannot answer common survey questions about a wide range of political phenomena, for example, dampens many observers' confidence in civic competence.

If citizens are simple and politics is complex, what is the optimal response for people who want greater civic competence? Actual responses vary. Many simply decry the situation, doing nothing more than bashing the masses for not being more interested in politics. A special few do something more constructive. They advocate mechanisms designed to change the amount and content of information available to target audiences. In short, they attempt to improve democracy by enhancing civic competence.

Scholars, legislators, and foundations both public and private advocate various means to enhance competence, including civic education campaigns and the development of informative web-sites. These efforts focus on important topics such as the relationship between smoking and lung cancer, the relationship between sexual activity and AIDS, the plight of distant populations, and the quality of voter and juror decisions, all in an effort to help citizens better understand the consequences of their actions. When such activities enhance civic competence, they constitute valuable resources for the public at large.

However, something is wrong with many of these attempts. The problem is that they are based on flawed assumptions about how citizens seek and process information. One manifestation of the problem is that many advocates of competence-generating proposals proceed as if merely providing new information is sufficient to improve competence. However, the transmission of socially relevant information is no "Field of Dreams." It is not true that "if you build it, they will come." Nor is it true that if they come, the effect will be as advocates anticipate.

Indeed, many efforts to improve civic competence provide information that target audiences ignore. Others produce information that only confuses those for whom greater clarity was intended. Either outcome entails serious consequences. In addition to the social costs that come from propagating extant civic incompetence, society pays a cost when entities capable of providing valuable public goods invest in schemes whose failure is anticipatable. Moreover, when advocates induce others to invest their time and energy in flawed competencegenerating mechanisms, they cause precious resources to be squandered. It is important, therefore, to understand when and how proposals to enhance civic

4. Some people use the term "competence" in a narrow, ideological manner-asserting that a set of statements with which they agree should be privileged in social decision-making. My use of the term is orthogonal to such uses. So, here, I neither support nor refute specific claims about the kinds of premises that should be privileged in political discussions. Instead, I clarify conditions under which the introduction of an information-generating device - such as a new opportunity for deliberation-leads any given piece of information to affect civic competence.

5. For a recent inventory of such findings, see Michael X. Delli CARPINI \& SCOTT KeEter, WHAT AMERICANS KNOW ABOUT POLITICS AND WHY IT MATTERS (1996).

6. FIELD OF DREAMS (Universal Studios 1989). 
competence will have the effects that advocates claim they will. With this point in mind, I turn to the topic of deliberation.

Many people claim that deliberation can enhance civic competence. Such claims are often based on arguments made by prominent philosophers and political theorists. The arguments conclude that an expanded use of deliberation in politics produces a number of tangible benefits, including increased civic competence.

A brief version of such arguments is as follows: Assembling groups of people with diverse abilities into settings that are designed to generate new information flows results in the less-knowledgeable participants gaining a broader and more accurate understanding of the consequences of their actions; participants not only learn more by increased exposure to the ideas of others, but the specter of public justification-having to justify one's own claims before an audience of equals - induces speakers to constrain the extent to which their arguments reflect their self-interests; thus, not only do deliberation participants receive new information, but they also receive content that is different from that which the media-or purely self-centered introspection-would provide.

Contemporary thinking on the benefits of expanded deliberation in politics focuses on the ideas of Jürgen Habermas, particularly his construction of an "ideal speech environment." Fishkin characterizes this environment as follows:

In this situation, all arguments are answered in a context of free and equal discussion. All arguments deemed relevant by anyone in the discussion are given as extensive a hearing as anyone wants and people are willing to consider all the arguments on their merits. We can imagine questions receiving a virtually unlimited amount of time so that, in the end, the only force leading to a resolution of any question is the "force of the better argument."

Are deliberative proposals, whether striving to achieve Habermas's or other ideals, capable of elevating the "force of the better argument" in citizens' political decision-making? Or are deliberative mechanisms themselves among the many competence-generating ideas that cannot live up to their advocates' advance billing?

There are reasons to doubt deliberation's advocates. Consider, for example, that deliberative groups must adopt explicit or implicit agendas that determine the order in which participants speak. Since statements must be made in some order, the phenomenon that psychologists refer to as "priming" can occur." If priming occurs in deliberative settings, what people learn from deliberation can depend as much on the order in which statements are made as they can on the

7. See generally JÜrgen HABERMAs, BETweEN FACTS AND NORMS (1996); JÜRgEN HABERMAS, THE THEORY OF COMMUNICATIVE ACTION (1984).

8. JAMES S. FISHKIN, THE VOICE OF THE PEOPle 40 (1995) (quoting Jürgen Habermas, A Reply to my Critics, in HABermas: CRITICAl Debates 218 (John B. Thompson \& David Held eds., 1982)).

9. Klaus Fiedler, Processing Social Information for Judgments and Decisions, in INTRODUCTION TO Social Psychology 133, 140-43 (Miles Hewstone et al. eds., 2d ed. 1996) (Priming occurs when a seemingly unrelated stimulus affects a subject's processing of subsequent information.). 
content of the statements themselves. ${ }^{10}$ Similarly, studies of complex systems, artificial intelligence, and organizational decision-making provide mixed messages about when one should expect activities such as deliberation to breed competence. Indeed, there are many situations in which the aggregation of opinions can decrease what individuals understand about the consequences of their actions (for example, the organizational malady known as "groupthink"). Studies of the incentive effects of institutions in political science and economics further reveal that explicit and implicit rules of a deliberative environment can dramatically affect how speakers represent their ideas, thus limiting what target audiences can learn. ${ }^{12}$

Such findings reveal as false the presumption that the more knowledgeable people in a deliberative environment are necessarily the more influential-even on average. As the alleged benefits of many deliberative devices depend on those with greater knowledge being more persuasive than those who lack knowledge, such findings can undermine important claims about the benefits of deliberation. Particularly imperiled is the claim that proposed deliberative mechanisms necessarily or even frequently elevate the "force of the better argument."

If deliberation advocates base their claims on unreliable assumptions, is there an alternate way for them to support their claims? And, if such a basis does exist, can it be of use to other people who make investments in competence-generating mechanisms, such as civic education campaigns and public service web-sites? In what follows, I answer both questions affirmatively. I base my answer on an examination of the relationship between deliberation and competence. The examination has two steps.

First, I evaluate Christopher Schroeder's argument about whether evidence of deliberation's benefits can be derived from its alleged similarity with legal decision-making. ${ }^{13}$ Schroeder begins with the premise that some deliberation advocates support their claims by referencing the superiority of legal decisions.

10. See E. Tory Higgins et al., Category Accessibility and Impression Formation, $13 \mathrm{~J}$. EXPERIMENTAL SOC. PSYCHOL. 141, 150-51 (1977); Barbara Tversky \& Michael Tuchin, A Reconciliation of the Evidence on Eyewitness Testimony: Comments on McCloskey and Zaragoza, $118 \mathrm{~J}$. EXPERIMENTAL SOC. PSYCHOL. GEN. 86, 89 (1989).

11. "Groupthink obtains when the decision process of a highly cohesive group of like-minded people becomes so overwhelmed by consensus seeking that their apprehension of reality is undermined." Eddy Van Avermaet, Social Influence in Small Groups, in INTRODUCTION TO SOCIAL PsYCHOLOGY 487, 518 (Miles Hewstone et al. eds., 2d ed. 1996). For a general and more multidisciplinary overview, see NATIONAL RESEARCH COUNCIL, LEARNING, REMEMBERING, BELIEVING: ENHANCING HuMAN PERFORMANCE (1994).

12. For a famous example of a class of models that set out a simple communicative environment in which preference divergence between a speaker and his target audience decreases what the latter learns from the speaker's statements, see Joel Sobel and Vincent Crawford, Strategic Information Transmission, 50 ECONOMETRICA 1431, 1437 (1982). See also ARTHUR LuPia \& MATHEW D. MCCUBBINS, The Democratic Dilemma: Can Citizens Learn What They NeEd To Know? (1998) (using models and experiments to clarify how the structure of political institutions affects who can learn what from whom).

13. Christopher H. Schroeder, Deliberative Democracy's Attempt to Replace Politics with Law, 65 LAW \& CONTEMP. PROBS. 95, 95 (Spring 2002). 
He then finds that important differences between legal and political decisionmaking render such references invalid. My evaluation is largely supportive of Schroeder's argument, although it differs on the issue of what to do next if he is correct. I contend that if the benefits of deliberation cannot be explained by a law-politics analogy, then our conclusion about them should consider other explanations.

Next, I present an alternate foundation for deliberation advocates' claims. I use empirical findings on human cognitive capacities and structural premises about the incentive effects of institutions to identify a set of necessary conditions for competence-generating mechanisms to produce desired outcomes. These conditions are not easily satisfied and stand in stark contrast to an assertion upon which many advocates' claims depend. The assertion is that making relevant information available, or promoting discussion between free and equal participants, is sufficient to boost competence. However, the necessary conditions that I identify reveal this assertion to be seriously flawed. While these necessary conditions expose serious barriers for those who advocate deliberative mechanisms, they also suggest engineering principles that can help people adapt to some of these barriers. I conclude that new ways of thinking are necessary to improve decision-making among those persons who seek to increase civic competence.

\section{II}

\section{DISCONNECTING DELIBERATION FROM LAW}

Perceived flaws in the means by which target audiences make decisions motivate people to advocate competence-generating mechanisms. For prominent deliberation advocates, one such flaw is that people pay too much attention to private interests when making decisions that have an impact on the public. Legislators, for example, are often depicted as lawmakers-for-hire, allowing interest-group favoritism and material self-interest to supplant public-motivated or scientific considerations as bases for decisions. ${ }^{14}$

Prominent deliberation advocates cite legal decision-making as entailing methods that constrain private interests in public decisions. They refer to the evidentiary presentations and discussions that precede the decisions of judges and juries, and conclude that such processes would improve political decisions. The Supreme Court's deliberative norms are particularly well-regarded, with eminent thinkers such as John Rawls citing them as an exemplary. ${ }^{15}$

Should people who want to improve civic competence by increasing deliberation be compelled by analogies to legal decision-making? Schroeder addresses this question in his article "Deliberative Democracy's Attempt to Re-

14. Id.

15. John Rawls, The Idea of Public Reason, in DeliberATIVE DEMOCRACY 93, 93 (James Bohman \& William Rehg eds., 1997). 
place Politics with Law." " His argument begins with the observation that "the theory of deliberative democracy sketches a model of politics that borrows significant elements from models of law and legal decision-making." ${ }^{17}$ He then examines the extent to which cited properties of legal decision-making provide reliable evidence of how prominent deliberative proposals will affect political decision-making. He concludes that "the analogy deliberative democracy draws between legal reasoning and political reasoning fails." "18

Schroeder supports his conclusion by comparing critical aspects of politics and law. He finds important differences between the kinds of legal decisionmaking environments referenced by prominent deliberation advocates, such as Amy Gutman and Dennis Thompson, and the political environments in which deliberation is alleged to be effective. ${ }^{19}$ In law, for example, "both civil and criminal legal systems separate their advocacy and judicial functions, assigning one to lawyers and other advocates, while assigning the other to judges, magistrates and other decision-makers." ${ }^{20}$ In politics, by contrast, "these two functions can reside in the same individuals ... the same people who petition the government for policy action are involved in making the decisions." ${ }^{21}$ Such differences imply that the norms and institutions that constrain private interests in law will be insufficient in politics. Put another way, legal institutions can impose requirements on their participants that political institutions cannot impose on theirs. So, requirements that are attractive to deliberation advocates and are incentive-compatible in law are not incentive-compatible in politics. ${ }^{22}$ As a result, we can expect differences in the effectiveness of deliberation in the political and legal settings.

Schroeder also shows that the incentives of legal decision-makers contradict what deliberation advocates want for political decision-makers. For example, he conveys accurately the desires of many advocates that "[d]eliberative citizens are required to be sincere in the arguments they advance. Arguments are not to be advanced merely for strategic purposes, as when some politician broadcasts allegations of disloyalty or scandal about an opponent without believing the allegations herself, but does so nonetheless because the allegations have been shown effective through polling or focus groups." ${ }^{23}$ Law, by contrast, encourages strategic argumentation-lawyers, while "under obligations not to deceive

16. Schroeder, supra note 13 .

17. Id. at 113 .

18. Id. at 108 .

19. Amy Gutmann \& Dennis Thompson, Democracy And DisagreEment 67, 93 (1996).

20. Schroeder, supra note 13 , at 113 .

21. Id. at 114 .

22. Id. at 128 ("[T]he structure that deliberativists seek to impose is one that can only be adopted by political actors as they engage in political practice. This is unlike the structure that politics imposes on the practice of law, where people engaged in legal practice come to it with its basic political structure in place. No institution or practice stands similarly prior to politics to impose the structure on politics that deliberativists seek. Deliberativists attempt to take out of political practice decisions that should be endogenous to that practice.").

23. Id. at 117 . 
the court with respect to facts," also have an "obligation to their clients to advance the best arguments for their clients' case."

Schroeder's effort disconnects claims about deliberation's benefits from analogies to law. He wants this conclusion to lead his readers to revise, in a negative direction, their estimates of deliberation's expected benefits, but he does not stop there. He then turns his attention to the costs of deliberation, concluding that they are higher than commonly realized. A challenge he poses to deliberation advocates clarifies his view on this matter:

Deliberative democracy still must confront a problem that any prescription to pursue a single objective faces: justifying its tradeoffs. Deliberative democracy's goals will consume many resources, and the activities competing with deliberation for those resources are highly valued. Justifying the trade-offs is therefore quite necessary-and very difficult. $^{25}$

Prominent deliberation proposals require citizens to spend large amounts of time listening to others' arguments. When the group is large and everyone is allowed to have a say - the type of venue in which some deliberation advocates are especially keen to spread their practice-such requirements can be particularly onerous. ${ }^{26}$ The costs of deliberation, however, include more than the time and energy citizens would have to take from other activities.

Schroeder points out that the costs for some proposals also involve a loss of freedom. Indeed, the masses are not yet clamoring for the deliberative proposals of scholarly elites. So, if deliberative requirements are implemented, should we really expect citizens to participate or to pay attention? If they do not, if deliberative effectiveness hinges on broad participation, and if the only way to achieve broad participation involves some form of compulsion, then effective deliberation entails a loss of individual freedoms - a substantial cost. Of course, pointing out the existence of such costs does not imply that delegation is incapable of producing net benefits. Schroeder is correct, however, to state that such personal freedom costs should be factored into any decision to invest in deliberation.

In sum, Schroeder concludes that claims about the benefits of deliberation that depend on analogies between legal and political decision-making are invalid because the quality of the analogy is insufficient. He also finds that prominent deliberative proposals impose larger costs than advocates claim or perhaps even realize. These findings are compelling.

I am less compelled by what Schroeder sees as an implication of these conclusions. Namely, he questions whether the spread of deliberative mechanisms in politics can be justified at all. Schroeder concludes that it cannot, and urges theorists currently engaged in deliberative advocacy to "turn their attention to

24. Id. at $117-18$.

25. Id. at 133 .

26. Gutmann \& ThOMPSON, supra note 19, at 40. See also Bruce Ackerman \& James Fishkin, Deliberation Day (Feb. 4, 2000) (unpublished manuscript, presented at the Deliberating About Deliberative Democracy conference, University of Texas, available at http://www.la.utexas.edu/conf2000/papers. html). 
constructive pursuits." ${ }^{27}$ Schroeder's demonstration that arguments for the benefits of greater deliberation cannot credibly be based on faulty analogies to law, however, implies nothing about the plausibility of other justifications. ${ }^{28}$ Evaluating alternative justifications is the constructive pursuit that is consistent with both Schroeder's argument and the goals of many deliberative advocates.

Advocates of competence-generating mechanisms and those who want to construct such mechanisms have incentives to be knowledgeable about the conditions under which they produce beneficial results. Such constructive pursuits should revolve around a more accurate understanding of the relationship between institutions, incentives, and decisions in settings that-unlike law-are suitable analogies to political communication.

III

\section{RECONNECTING DELIBERATION TO BETTER FOUNDATIONS}

Many advocates of competence-generating mechanisms are motivated by the idea that a target audience lacks the information it needs to make competent choices in an important choice domain. Schroeder has demonstrated that analogies to legal decision-making do not provide a reliable basis for assessing the costs and benefits of competence-generating mechanisms. ${ }^{29}$ Can other evidence fill the void?

In this section, I describe how advocates and critics can better assess the likely benefits of competence-generating mechanisms. The method that I advocate focuses attention on a set of conditions that mechanisms must satisfy if they are to generate the kinds of outcomes that advocates desire. In particular, I focus on identifying necessary conditions for the claim that a particular mechanism "advantages the force of the better argument."

\section{A. Existence Conditions}

For a mechanism to advantage the force of the better argument, it is first necessary that there, in fact, be "a better argument." In political contexts, the existence of such arguments motivates interesting debates. Since much of my argument shows how difficult advantaging such arguments is, at this juncture I give advocates the benefit of the doubt and proceed as if such arguments do indeed exist.

27. Schroeder, supra note 13 , at 155 .

28. It is inevitable that some theorists will respond by contending that implementing deliberative strategies produces a procedural justice whose benefits-even if they have no consequences for outcomes or for eliminating the role of private interests - more than justify the costs, even if the costs are as high as Schroeder suggests. When such reactions come, they should be treated as question-begging, for if deliberation cannot be justified in terms of tangible outputs (that is, different individual choices or social outcomes), then it does not merit the human and capital resources that would have to be invested in it to make it work. This is the substantive point of Schroeder's argument and of my own.

29. Schroeder, supra note 13 , at $99,119$.

30. See Fishkin, supra note 8. 
It is also necessary that a competence-generating mechanism include at least two types of participants: those who would come to a deliberative session possessing the better argument and those who would not-for if everyone comes to the session possessing the argument, then there are no students. And, if no one comes to the session possessing the argument, then there are no teachers. In addition, participants must be allowed to communicate in ways that do not arbitrarily prevent the better argument from being conveyed or received. Deliberative theorists' call for recognizing all participants as free and equal is usually sufficient to satisfy this condition. Such attributes, however, are not sufficient to satisfy the necessary conditions that follow.

\section{B. Persuasive Conditions}

To advantage the force of the better argument (again employing an accounting scheme favorable to advocates), it is necessary that the mechanism cause the people with the better argument to persuade at least some people who did not initially possess the argument to do so. ${ }^{31}$ At the same time, the mechanism should not cause people who initially possess the better argument to be persuaded against it. If, for example, the better argument is that "choosing $A$ is best for everyone," then the mechanism should not persuade people to replace that belief with a contrary one. ${ }^{32}$

What conditions are necessary for a competence-generating mechanism to produce such patterns of persuasion? To answer this question, it is helpful to think about the currency of exchange in communicative environments. I refer to this currency as an utterance-a cluster of sounds or images that people use to convey ideas.

A casual view of human communication treats utterances as if they allow ideas to travel from one mind to another unadulterated, as if the ideas motivating the utterance are absorbed en masse. Yet this view is contradicted by a basic fact about human communication-all but the simplest utterances are parsed: People assign meaning to a word, a sentence, a paragraph, or a speech by breaking it down and paying attention only to some parts while ignoring others. $^{33}$ For example, whether reading a newspaper or watching a television pro-

31. Persuasion is "human communication designed to influence others by modifying their beliefs, values, or attitudes." Herbert W. Simons, Persuasion: Understanding, Practice, AND ANALYSIS 21 (1976).

32. I use the term "belief" to reference a concept that psychologists often call "attitudes" and economists often call "preferences." My motivation is that we are focally concerned with an individual's orientation towards an object and with the conditions under which the orientation can change. The orientation will be based in part on beliefs about what will happen as a result of interactions with the object and beliefs about how the person will feel given potential outcomes of that interaction. Across the social sciences, there are big differences in the labels used to express these concepts. My choice of terminology is motivated by a desire to clarify important aspects of belief/attitude/preference change in an intuitive and brief manner for a multidisciplinary audience.

33. SteVen Pinker, The LAnguage InStinct 196-222 (1994). Indeed, the same point can be made about a much wider range of environmental stimuli that includes, for example, images. See PATricia S. Churchland \& TERRENCE J. SEJNOWSKi, The COMPUTATIONAL BRAIN 141-238 
gram, each person varies in the attention that he or she pays to certain aspects of it. One does not simply consume all of the content as a whole, but instead picks apart and breaks down the presentation.

For a competence-generating mechanism to advantage the force of the better argument, it is necessary that a speaker's target audience parse utterances in a way that allows the better argument to supplant the argument it initially held. Many advocates of deliberation overlook this requirement. Doing so is equivalent to assuming that persuasion is a seamless process for which universal aspects of how people parse utterances present no important complicationswhich is in error.

\section{Success Requires Three Cognitive Victories}

Many researchers examine why, when, and how one person can persuade another to change his or her ideas. Psychologists conduct laboratory experiments that document correspondences between the attributes of a speaker, or his utterances, and the reactions of his target audience. ${ }^{34}$ Economists construct models of strategic communication that clarify how factors like self-interest and competition affect the kinds of utterances that others will find credible. ${ }^{35}$ Cognitive scientists develop neural networks that document the kinds of experience patterns or motivation an organism would need to change its orientation toward its environment. ${ }^{36}$ These and other scientific literatures provide important insights as to when and how persuasion can occur. ${ }^{37}$ As such, they provide evidence useful for understanding when a competence-generating mechanism can advantage the force of the better argument.

Collectively, this work shows that if a competence-generating mechanism is to increase a target audience's competence, it must also satisfy three additional necessary conditions:

(1991); see also ERIC R. KANDEL ET AL., ESSENTIALS OF NEURAL SCIENCE AND BEHAVIOR 387-406 (discussing the parsing of visual images); id. at 667-94 (discussing the processing of language).

34. See generally CARL I. HOVLAND ET AL., COMMUNICATION AND PERSUASION: Psychological StUdies of OpInION Change (1953); William J. McGuire, Attitudes and Attitude Change, in HANDBOOK OF SOCIAL PsYCHOLOGY (Elliot Aronson \& Gardner Lindzey eds., 1985).

35. At least two sets of economic literature are relevant. The first addresses strategic communication. See, e.g., Jeffrey S. Banks, Signaling Games in Political Science (1991); A. Michael SPENCE, MARKET SigNALING: INFORMATIONAL TRANSFER IN HIRING AND RELATED SCREENING PROCESSES (1974); Vincent Crawford \& Joel Sobel, Strategic Information Transmission, 50 ECONOMETRICA 1431 (1982). The second set of literature concerns mechanism design. See, e.g., Roger Myerson, Mechanism Design by an Informed Principal, 51 ECONOMETRICA 1767 (1983); Thomas R. Palfrey, Implementation in Bayesian Equilibrium: The Multiple Equilibrium Problem in Mechanism Design, in 1 ADVANCES IN ECONOMIC THEORY: SIXTH WORLD CONGRESS (Jean-Jacques Laffont ed., 1992)

36. Churchland \& Sejnowski, supra note 33, at 96-102; ANDY Clark, Associative ENGINES: CONNECTIONISM, CONCEPTS, AND REPRESENTATIONAL CHANGE 17-23 (1993).

37. See e.g., Political Persuasion And Attitude Change (Richard A. Brody et al. eds., 1996); Samuel L. Popkin, The Reasoning Voter: Communication and Persuasion in Presidential CAMPAigns (1991); James L. Gibson, A Sober Second Thought: An Experiment in Persuading Russians to Tolerate, 42 AM. J. POL. SCI. 819 (1998); Shanto Iyengar \& Nicholas Valentino, Who Says What? Source Credibility as a Mediator of Campaign Advertising, in ELEMENTS OF REASON: COGNITION, CHOICE AND THE BOUNDS OF RATIONALITY (Arthur Lupia et al. eds., 2000). 
(1) The better argument must win the battle for attention.

(2) The better argument must win the battle for memory.

(3) The better argument must win the battle at the precipice of choice.

These cognitive battles represent themes in the research described above that are most relevant to questions about when competence-generating mechanisms have desired effects.

1. The Battle for Attention. When one person attempts to convey an idea to another, the utterance is but one of many stimuli to which the target person can attend. In the battle for attention, an utterance must fend off competitors such as aspects of prior or future events with which a person may be preoccupied, the simultaneous actions or utterances of others, background noise, the color of the wallpaper, and so on. For the utterance to deliver a specific idea, the target audience must also pay particular attention to the parts of the utterance necessary to convey the idea. For example, if someone says, "George Bush pulled the United States out of the Anti-Ballistic Missile Treaty," and if knowing that this fact is essential to possessing "the better argument," then the target audience must parse the utterance in a way that leads them to adopt this particular view of the relationship between Bush, the United States, and the Treaty. If the target audience focuses exclusively on one aspect of the statement-for example, on Bush's other policy preferences - then exposure to the utterance will not advantage the better argument because attention will never have been paid to it.

The fact that paying attention to an utterance precludes paying attention to other stimuli in one's environment implies that attention is associated with what economists call opportunity costs-a metric for sacrificed opportunities. Such opportunity costs give people an incentive to direct their attention in ways that make such sacrifices beneficial. Stimuli that are very likely to cause a large increase in the pleasure, or a large decrease in the pain, that one experiences will be advantaged. ${ }^{38}$ For example, people in the path of a fast-moving train have an incentive to direct much of their attention to any stimulus that will help them to avoid the train. If the better argument can be conveyed through utterances that appear to provide greater decreases in pain or increases in pleasure than other available stimuli, then it will win the battle for attention. If, by contrast, the audience views the utterance less urgently, the better argument will not get attention.

Moreover, if adopting the better argument requires attention to a complex string of utterances-some of which are not seen as urgent-then the argument's battle for attention can be harder to win. Such dynamics underlie the phenomena that psychologists and political scientists refer to by names such as priming, framing, and agenda setting - phenomena featuring an early part of an utterance that changes the manner in which people attend to, and otherwise

38. LUPIA \& MCCUBBINS, supra note 12 , at 21-30. 
process, later elements of the utterance..$^{39}$ If, for example, priming causes a person to ignore the latter part of an utterance, and if understanding the better argument requires attention to the latter part, then priming prevents the better argument from being advantaged. The phenomenon labeled "cognitive dissonance" can have related effects as people who anticipate that an utterance will produce an aversive emotional state may ignore the utterance in an attempt to avoid the state. ${ }^{40}$

Other research provides important clues about how people choose the utterances to which they attend. One clue from linguistics is the fact that most ideas can be expressed in multiple ways. ${ }^{41}$ So, if a speaker wants to persuade others to adopt the better argument, he may have an incentive to present the idea in a particular way. That is, he may have an incentive to condition his utterance on the audience's likely reaction. At the same time, the audienceknowing that most words have multiple meanings - may need to seek additional information about the circumstance that produced the utterance in order to infer its meaning. In politics, where who a particular argument benefits can provide valuable information about whether believing it is personally beneficial, the audience may have an incentive to condition its reaction to the utterance on the speaker's motivation for offering it. If, for example, I know that you and I have the same preferences regarding trade policy with Mexico, then I may use this information to derive a meaning from your utterance that I might have interpreted differently had I known us to have conflicting interests. Such communication is properly categorized as a strategic interaction.

Anyone who observes legal argument, legislative debate, negotiations, or a political campaign does not need to be told that participants are strategic in how they choose what to say and what to believe. Game-theoretic analyses of such situations show that if a target audience perceives a speaker to have sufficiently conflicting interests, or no expertise on the issue at hand, then it will ignore the speaker's utterances. ${ }^{42}$ Such analyses parallel efforts in psychology that identify which speaker attributes (for example, a reputation for being trustworthy) affect persuasiveness. ${ }^{43}$ Since an audience is often uncertain about such attributes, perceptions of these attributes drive how audiences parse utterances. ${ }^{44}$ So, even

39. See, e.g., James N. Druckman, The Implications of Framing Effects for Citizen Competence, 23 Pol. BehaV. 225 (forthcoming 2002); David O. Sears, Symbolic Politics: A Socio-Psychological Theory, in EXPLORATIONS IN POLITICAL PSYCHOLOGY 113 (Shanto Iyengar \& William J. McGuire eds., 1993).

40. LeOn Festinger, A THEORY OF COGNitive DissonAnCE (1957).

41. For different views on the correspondence between ideas and their expression, see GEORGE LAKOFF, WOMEN, FIRE, AND DANGEROUS THINGS: WHAT CATEGORIES REVEAL ABOUT THE Mind (1987); STEVEN PINKER, WORDS AND RulES: THE INGREDIENTS OF LANGUAGE (1999).

42. LUPIA \& MCCUBBINS, supra note 12, at 54-55; Crawford \& Sobel, supra note 35, at 1448.

43. DANiel J. O'KeEFe, Persuasion: TheORY AND ReseArCH $130-57$ (1990).

44. LUPIA \& MCCUBBINS, supra note 12 , at 50-51. 
if a speaker possesses the better argument, his or her low perceived credibility can prevent the better argument from prevailing. ${ }^{45}$

I have listed only a few hurdles that the "better argument" must overcome to win the battle for attention. Many mistakes about the likely success of a competence-generating mechanism can be avoided by paying greater attention to "attention." For example, many people proceed as if their mechanism is akin to a "Field of Dreams," believing that "if you build it, they will come." As Schroeder points out, there are already many opportunities for civic engagement and most operate at far less than full capacity. ${ }^{47}$ In a world where any particular issue is one of many potential concerns, winning the battle for attention will be difficult. But for a mechanism to increase competence, the battle cannot be ignored-it must be waged.

2. The Battle for Memory. Once a stimulus earns attention, it must be processed. If it is processed in certain ways, aspects of it can be stored in memory and retrieved for future use. If it is not processed in these ways, it is-from a cognitive perspective-gone forever. If it is gone forever, it provides no basis for new beliefs. This is simply another way of saying that persuasion does not occur. $^{48}$ For this reason, a necessary condition for a competence-generating mechanism to advantage the force of the better argument is that the utterance carrying the argument be parsed in a way that produces a unique residue in memory.

Several lines of social scientific research reveal how we can make better predictions about when something such as "the better argument" will win the battle for memory. Examples include the "Elaboration Likelihood Model" and the "Heuristic Systematic Model" from social psychology. ${ }^{49}$ Each model draws inferences from combinations of theory and experiment and reveals that if a stimulus is sufficiently engaged (that is, the central/systematic route of information processing is activated), it will leave a stronger and more robust residue in memory.

45. This phenomenon appears to affect jury decision-making. There, the proportion of high socioeconomic-status white males selected to act as jury foremen is extraordinarily unrepresentative of their numbers in the general juror population. Phoebe Ellsworth, Are Twelve Heads Better Than One? 52 LAW \& CONTEMP. PROBS. 205, 213 (1989). Whether this difference is consequential for the jury's competence depends on the extent to which the foremen are more likely to possess better arguments and be more persuasive than other jurors.

46. FIELD OF DREAMS (Universal Studios 1989).

47. Schroeder, supra note 13 , at 112 .

48. I depict memory here as consistent with the fact that a process in a stimulus can create a new memory that is not necessarily the stimulus itself. My motivation for this phrasing is work on on-line processing, which demonstrates that a stimulus can affect beliefs (and attitudes) without the stimulus itself being memorized. Reed Hastie \& Nancy Pennington, Notes on the Distinction Between MemoryBased versus On-Line Judgments, in ON-LINE COGNITION IN PERSON PERCEPTION 1, 6 (John N. Bassili ed., 1989).

49. See Alice H. Eagly \& Shelly Chaiken, The Psychology of Attitudes 326-28 (1993) ("Heuristic Systematic Model"); Richard E. PetTy \& John T. CACIOPPO, COMMuniCATION AND Persuasion: Central AND Peripheral Routes to Attitude Change 5-23 (1986) ("Elaboration Likelihood Model"). 
In other words, when people take the time to contemplate what a speaker says (that is, when they generate internal counter-arguments for the purpose of comparison or when they elaborate), these aspects of the utterance are more likely to be coded as distinct from prior aspects of memory. These aspects of the utterance are, as a result, more likely to survive as distinct new memories. The alternative (peripheral/heuristic) route, by contrast, entails processing of details from which inferences are easily drawn (for example, noticing that an endorsement comes from the Sierra Club rather than reading the content of the argument.) When an audience does not take the time to elaborate on an utterance, however, the utterance is less likely to generate distinct memories.

If an utterance does not generate a distinct memory, then the audience's beliefs must be derived from only old memories. ${ }^{50}$ Put another way, if the utterance does not generate new memories, then the mechanism cannot advantage the better argument. By implication, the many advocates of competencegenerating mechanisms who implicitly assume that an audience will use the central route to process utterances are likely to have erroneous and unduly optimistic expectations about their endeavors. Many other lines of research about memory carry the same lesson-it is wrong to simply assume that a stimulus that wins the battle of attention also wins the battle of memory. ${ }^{51}$

3. The Battle at the Precipice of Choice. Suppose that all of the necessary conditions listed above have been satisfied. Suppose, that is, that a better argument exists; that we have given some who possess the argument the opportunity to communicate with some who do not; that the better argument is communicable; and that utterances containing the better argument have won the battles for attention and memory. In such a case, at least one more condition must be satisfied for the mechanism to advantage the force of the better argument.

This is the "battle at the precipice of choice," where the choice in question ranges from which vote to cast to which opinion to defend in conversations with others. For the better argument to be advantaged-to lead to a change in a future choice-it must replace a prior belief. So, if the better argument is "blue is the best color of all," and if the mechanism is to advantage the argument, then the mechanism must lead this argument to replace beliefs such as "red is the best color of all"; or "there is some chance that blue is the best color of all, but I am not certain"; or to create a new belief for targets who have never before contemplated the correspondence.

50. For a particularly good example of the ways in which utterances are reconstructed in the mind, see MARK TURNER, COGNITIVE DiMENSIONS OF SOCIAL SCIENCE 63-70 (2001).

51. Milton Lodge \& Charles Taber, Three Steps Towards a Theory of Motivated Reasoning, in ELEMENTS OF REASON: COGNITION, CHOICE, AND THE BOUNDS OF RATIONALITY 183, 184 (Arthur Lupia et al. eds., 2001) ("The clear expectation is that most, if not all, citizens will be biased reasoners, finding it nearly impossible to evaluate any new information in an evenhanded way. The tendency is to evaluate incoming information to support preconception and to devalue contrary evidence."). 
Thus, the final battle is between old beliefs and new ones. When people are motivated to hold correct beliefs, victory depends on the extent to which the new beliefs better correlate with prior observations. ${ }^{52}$ If an argument contains elements easily shown to be false, its credibility is less. If prior experience or relevant analogies provide only supportive evidence, then its credibility is greater. Without this final victory, any advantage the mechanism offers to the better argument is inconsequential to the target audience's future actions. As a result, the mechanism cannot affect the target audience's competence..$^{53}$

\section{Implications for Deliberation}

Deliberative strategies are members of a class of mechanisms that people advocate as effective ways to counter perceived civic incompetence. These mechanisms require investments of effort and capital to be effective. If such investments are based on flawed assumptions - such as those derived from analogies to law or based on folk theories of how we learn-and if there are other valuable endeavors to which the resources could have been directed, then the consequences of those well-intentioned mistakes are tragic. Those who study topics such as deliberation can use their skills to reduce the number and magnitude of these tragedies.

Paying greater attention to the necessary conditions listed above can help both theorists and practitioners achieve this aim. At a minimum, merely recognizing that such conditions exist can dissuade people from assuming that providing new opportunities for information transmission is equivalent to improved civic competence. Greater attention to these conditions will have the added benefit of generating questions that advocates of competence-generating mechanisms should ask if they want to reconcile their claims about performance with the actual capacity of the devices they support.

I advocate greater attention to these necessary conditions as a way to improve the competence of those who seek to improve civic competence. By the standards set forth above, if my allegedly better argument is to persuade my target audience, then it must defeat their old beliefs about what makes mechanisms effective. I close this section by presenting one common set of old beliefs and explaining why it should be abandoned.

\section{E. A Memory and A Folk Theory That Induce Undue Optimism}

Many people are over-optimistic about the likely benefits of competencegenerating proposals because they base their projections on flawed foundations.

52. Wolfgang Stroebe \& Klaus Jonas, Attitude Formation and Strategies of Change, in INTRODUCTION TO SOCIAL PSYCHOLOGY 240, 257-58 (Miles Hewstone et al. eds., 2d ed. 1996).

53. Moreover, if an argument other than the better one is able to prevail at this juncture, then persuasion can occur, but competence can fall. Suppose, for example, that we want to improve a target's ability to get from point $A$ to point $B$ in a specific amount of time. If the most persuasive people in the room (that is, the people perceived to be the most knowledgeable and trustworthy) do not, in fact, possess the better argument (that is, they think they know the way, but they are mistaken), then mechanisms that facilitate deliberation can reduce the target's competence. 
Schroeder showed analogies to legal decision-making to be one such foundation. I will set forth another.

Almost everyone can remember times when they did not know something that they now know. For some readers, one of those times will occur within seconds. In the United States and Europe, it is common to believe that warm places lie south of cold places. As a result, many people do not know that Venice, Italy (a place known for lovely gondolas traversing its flowing canals) is north of Buffalo, New York (a place known for long, harsh winters), and that often-cold Denver, Colorado is south of often-warm Rome.

In every person's memory, times of not knowing what they now know are accompanied by moments of discovery - times when they are presented with new information that contradicts and then changes their prior beliefs. Such memories reinforce $a$ widely shared folk theory of how people learn: Take ignorance, add information, and then gain competence at tasks such as knowing which of two remote cities is farther north. The human ability to recall such sequences is nearly universal. So is the ability to describe them. As a result, the folk theory is easy to communicate. Relative to more complex explanations of how we learn, we should expect this one to suffice in casual conversations in which the cost of being incorrect is insubstantial.

But the folk theory can be deceptive. The deception takes the form of inducing people to derive a causal story about how people learn from data insufficient for that task. The deception is a consequence of what statisticians call "selecting on the dependent variable." In other words, people recall the cases where the theory is accurate (for example, we start incompetent at a particular task; we pay attention to a new piece of information; it changes our views, and we then gain the ability to accomplish the task) and not cases in which it fails (for example, we start, incompetent, at a particular task, we either ignore new information or use it in a way that does not increase our intelligence, and we, therefore, gain no task-relevant abilities).

We select the dependent variable described above not on purpose, but because the "state of not knowing something that we now know, moment of discovery" sequence is advantaged in memory. Its advantage comes from the fact that it is built only from events that have occurred..$^{54}$ The theory-countering sequence of "state of not knowing something that we now might have known, moment of learning what we would have known had attended or reacted to the information in a different way," by contrast, contains counterfactuals-objects not directly retrievable from memory. Counterfactual construction requires

54. In other words, the cognitive act of attempting to construct a causal story of the form " $A$ causes $B$ " requires access to states "not $A$ and not $B, A$ and $B$." If either of the two states "not $A$ and not $B$ " and " $A$ and $B$ " is impossible to access, then the sequence cannot be constructed and the causal story cannot emerge. On basic properties of memory, see KANDEL ET. AL., supra note 33, at 651-63. For a recent review of what flaws in memory imply for legal decision-making, see DANIEL L. SCHACTER, THE SEVEN SINS OF MEMORY: HOW THE MIND FORGETS AND REMEMBERS 91-98 (2001) (focusing on properties of misattribution). 
substantial cognitive effort, effort that comes only if a person is sufficiently motivated. ${ }^{55}$

I contend that many people can more easily recall instances in which more information led to greater competence than they can instances in which such attempts failed. The consequence of this tendency is to overestimate the extent to which "take ignorance, add information, and then gain competence at tasks such as knowing which of two remote cities is farther north" is a valid analogy to a proposed mechanism's performance. Such tendencies explain many advocates' resistance to contemplating what features are necessary or sufficient for their proposal to produce desired outcomes.

Indeed, a problem with many claims made by advocates of deliberation and other competence-generating proposals is that they are disconnected from empirical work on belief change in the social and cognitive sciences. They do not attend to discoveries regarding aspects of perception, attention, and retention that affect how people process new information. By ignoring this literature, advocates cannot articulate what conditions are necessary and/or sufficient for their proposal to cause any particular belief or behavior change. It is therefore not surprising that the returns to investment in competence-generating proposals are so poorly understood.

Fortunately, an alternative strategy is available. The social and cognitive sciences are providing a set of cognitive and psychological universals from which those who theorize about or attempt to build competence-generating mechanisms can derive principles of effective design. By paying closer attention to the circumstances under which an utterance wins and loses the battles of attention, memory, and choice, people who want to enhance civic competence can allocate their scarce resources more effectively and efficiently. ${ }^{56}$

\section{IV}

\section{CONCLUSION}

This essay is devoted to clarifying how competence-generating mechanisms work. Its preliminary goal is to steer those who want to build civic competence away from flawed analogies in legal decision-making and unreliable folk theories of learning. Its primary goal is to steer those same people toward a more productive and constructive way of thinking about building civic competence. That is why I advocate greater attention to fundamental properties of proposed and extant competence-generating mechanisms.

55. PETTY \& CACIOPPO, supra note 49, at 81-90. For other articles focusing on the correspondence between motivation and cognition, see THE PSYCHOLOGY OF ACTION (Peter M. Gollwitzer \& John A. Bargh eds., 1995).

56. For recent examples of work on the topic of deliberation, see JOSEPH HEATH, Communicative ACTION ANd Rational Choice (2001); James Johnson, Arguing for Deliberation: Some Skeptical Considerations, in DELIBERATIVE DEMOCRACY (Jon Elster ed., 1988); Lynn Sanders, Against Deliberation, 25 POL. THEORY 347 (1997); Michael A. Neblo, Thinking Through Democracy: Deliberative Politics in Theory and Practice (2000) (Ph.D. Dissertation, University of Chicago) (on file with author). 
I believe that there are conditions in which deliberation can have many of the effects that its advocates claim. I also find conditions under which deliberation can have no effect, as well as effects that are counterproductive to its advocates' aims. For deliberation, and for the construction of civic competence generally, the road to progress lies in learning how to tell the difference. In other words, progress will ultimately come from arguments that bind themselves to practical relevance through a commitment to building from scientific discoveries. 